\title{
Evaluation of Humanities and Social Science Research Efficiency of the Normal Universities in China
}

\author{
Huibin Cui, Yongqi Huang* \\ Economics and Management School, South China Normal University, Guangzhou 510006, Guangdong, China \\ *Corresponding author
}

\begin{abstract}
The prosperity of humanities and social science is a significant driving force for the improvement of technology thus contributing to construct the national innovation system with Chinese characteristics. By utilizing the three-stage DEA model, this article measured and evaluated the research efficiency of humanities and social science in 98 normal universities in China. The results show that the research efficiency of humanities and social science in these 98 normal universities is not high in general and highly differs from each other. Meanwhile, inefficiency mostly caused by the internal management system is obvious. Hence, how to improve the inner management and strengthen the synergy of the corresponding subject is an important target for those normal universities.

Keywords: Normal universities, Humanities and social science, Research efficiency, Three-stage DEA model
\end{abstract}

\section{INTRODUCTION}

The establishment of modern economic system depends on high-quality development of economy, which requires that the mode of economic growth change from relying on the input of factors of production to become innovation-driven, and a national innovation system with independent innovation ability is in urgent need. In terms of specific connotation, innovation system can be divided into two types, technology innovation system that is driven by technological progress, and institutional innovation system that coordinates the technology development to maximize the efficiency of technological innovation. In between the two innovation system, improvement of technology innovation system is directly promoted by the improvement of science and technology while the progress of the institutional innovation system is inseparable from humanities and social science. Only when the two complement each other and promote each other can a series of problems such as duplication of resources, dispersion of research strengths and unclear function positioning of the main body of innovation be solved, and the overall effectiveness of the national innovation system get continuous improvement. Specifically, original humanities and social science theories play an important part in policy-making and construction of systems, optimizing incentive mechanism and management. So there`s prominent meaning following with interest the development of humanities and social science.

Colleges and universities are significant carriers to set up and perfect the national innovation system, powering the enhancement of national innovation capabilities. With the country's emphasis on higher education and the in-depth implementation of the "Double first-class" project, colleges and universities are increasingly recognized as drivers of innovation and sustainable development, pushing forward policy formulation and implementation [1]. There are a large number of colleges and universities in China, and the characteristics of training talents, research advantages, and subject settings also vary depending on the social division of labor. Normal colleges and universities have the longest history in China. Traditional normal colleges and universities mainly refer to colleges and universities that train various teachers for elementary education. With the development of society, the normal universities have also transformed into comprehensive and research universities. It should be said that they are the universities closest to the nature of education, and they are also an important force for undertaking research and innovation tasks related to humanities and social sciences [2]. Scientifically evaluating the efficiency of humanities and social science research in normal universities can not only provide a reference for grasping the scientific research status of humanities and social sciences in Chinese universities, but also can further explore ways to improve the efficiency of humanities and social science research in normal universities, laying a solid foundation for comprehensively promoting the prosperity of disciplines and building a national innovation system with Chinese characteristics.

The rest of this article is structured as follows. In section 2 we elaborate the three-stage DEA model which has obvious advantages in evaluating the research efficiency of the universities, for example, it can effectively eliminate the influence of environmental factors and statistical noise, and thus being widely used $[3,4]$. Section 3 explains the indexes and data sources of this article. Next, section 4 employs the three-stage DEA model to measure the efficiency of humanities and social science research in normal universities and draw the overall 
picture of scientific research efficiency of 98 normal universities in China. Finally, section 6 is dedicated to the findings from a policy perspective.

\section{METHOD}

Data envelopment analysis is a non-parametric technical efficiency method based on the relative comparison between the evaluated units, first proposed by Charnes, Cooper and Rhodes in 1978, and the first model of DEA named CCR was also derived from this [5]. DEA, using linear programming technique to solve the efficiency frontier, does not require the assumption of functions and distributions in advance, and reduces the impact of subjective judgment on the efficiency evaluation since there is no need to weight multiple input and multiple output. Therefore, it is especially applicable to the efficiency evaluation of multiple input and multiple output [6]. But the traditional single-stage DEA is only applicable to output and input to obtain the preliminary efficiency value of the decision-making unit (DMU). However, the efficiency of the DMU is influenced by the following three aspects: the management efficiency, the features of the environment in which production activities are conducted and statistical noise. Management efficiency is endogenous, while environmental conditions and statistical noise are exogenous. So it is necessary to decompose the effect of these three factors in production efficiency [7]. Based on the logic above, Fried put forward the three-stage DEA model to disentangle the three influences on production efficiency and finally eliminate the effects of environment and statistical noise to obtain a more accurate efficiency of decision-making unit.

To purge humanities and social sciences research efficiency in normal colleges and universities of environmental effects and statistical noise, so as to evaluate the scientific research efficiency of normal colleges and universities in China objectively and truthfully, and to find informative results to help improve the scientific research efficiency of normal colleges and universities, this article adopts Fried's three-stage DEA approach to study the scientific research efficiency of normal universities in China.

\subsection{Stage 1: The Traditional DEA}

In the first stage, DEA model was applied to observed input and output data and get an initial evaluation of efficiency. The traditional DEA can be divided into two types: CCR and BCC. Compared with the CCR model, which assumes that returns to scale are unchanged, the BCC model is based on variable returns to scale, facilitating further discussion that whether the efficiency status of DMUs is mainly affected by pure technical efficiency or scale efficiency. In addition, considering that the input is artificially controllable, this article employs the input-oriented BCC model as the basic model for the three-stage DEA. At this stage, technical efficiency (TE), pure technical efficiency (PTE) and scale efficiency (SE) of the decision-making unit can be obtained, where the scale efficiency is equal to the technical efficiency divided by the pure technical efficiency; and difference between target input and observed input quantities, the input slack is obtained too.

\subsection{Stage 2: Using SFA (Stochastic Frontier Analysis) to Decompose Stage 1 Slacks}

Fried [7] pointed out that we should interpret the slacks in Stage 1 in terms of three aspects: environmental influences, managerial inefficiencies, and statistical noise. So decomposing slacks of Stage 1 into this three effects is what we have to do in Stage 2, which can be achieved using SFA.

Firstly, regression of stage 1 slacks against the observable environment variable was performed by means of [7]:

$$
s_{n i}=f^{n}\left(z_{i} ; \beta^{n}\right)+v_{n i}+u_{n_{i}}, n=1,2, \ldots, N ; i=1,2, \ldots, I .
$$

Where $s_{n i}$ is the slack of the $n^{\text {th }}$ input for the $i^{\text {th }}$ producer while $\mathrm{f}^{\mathrm{n}}\left(\mathrm{z}_{\mathrm{i}} ; \beta^{\mathrm{n}}\right)$ are deterministic feasible slack frontiers which capture the impact of the environment on Stage 1 slacks. Besides, $z_{i}$ represents environment variables, whose coefficients are expressed by parameter vector $\beta^{\mathrm{n}}$. $\left(\mathrm{v}_{\mathrm{ni}}+\mathrm{u}_{\mathrm{n}_{\mathrm{i}}}\right)$ represents a composed error structure with the assumption that the $\mathrm{v}_{\mathrm{ni}} \sim \mathrm{N}\left(0, \sigma_{\mathrm{vn}}^{2}\right)$ reflect statistical noise and that $\mathrm{u}_{\mathrm{n}_{\mathrm{i}}} \geq 0$ reflect managerial inefficiency.

The estimator of $\mathrm{u}_{\mathrm{n}_{\mathrm{i}}}$ can be obtained by the equation provided by Luo Dengyue [8]:

$\mathrm{E}\left[\mathrm{u}_{\mathrm{n}_{\mathrm{i}}} \mid \mathrm{v}_{\mathrm{n}_{\mathrm{i}}}+\mathrm{u}_{\mathrm{n}_{\mathrm{i}}}\right]=\frac{\sigma \lambda}{1+\lambda^{2}}\left[\frac{\phi\left(\frac{\varepsilon_{\mathrm{i}} \lambda}{\sigma}\right)}{\Phi\left(\frac{\varepsilon_{\mathrm{i}} \lambda}{\sigma}\right)}+\frac{\varepsilon_{\mathrm{i}} \lambda}{\sigma}\right]$.

in which $\lambda=\frac{\sigma_{u}}{\sigma_{v}}, \varepsilon_{\mathrm{i}}=\mathrm{v}_{\mathrm{n}_{\mathrm{i}}}+\mathrm{u}_{\mathrm{n}_{\mathrm{i}}}$. Then the estimator of $\mathrm{v}_{\mathrm{n}_{\mathrm{i}}}$ can be separated from the composed error structure [7]:

$\widehat{\mathrm{E}}\left[\mathrm{V}_{\mathrm{n}_{\mathrm{i}}} \mid \mathrm{v}_{\mathrm{n}_{\mathrm{i}}}+\mathrm{u}_{\mathrm{n}_{\mathrm{i}}}\right]=\mathrm{s}_{\mathrm{n}_{\mathrm{i}}}-\mathrm{z}_{\mathrm{i}} \widehat{\beta}^{\mathrm{n}}-\widehat{\mathrm{E}}\left[\mathrm{u}_{\mathrm{n}_{\mathrm{i}}} \mid \mathrm{v}_{\mathrm{n}_{\mathrm{i}}}+\mathrm{u}_{\mathrm{n}_{\mathrm{i}}}\right]$

After the separation, the input variables will be adjusted to the same operating environment and statistical noise according to SFA results. And there are two ways to achieve fair competition. One is to adjust downward the input of the decision-making unit with relatively unfavorable environment or relatively bad luck and the extent of reduction determined by how much they are disadvantaged. Another approach is to adjust upward the input of decision-making unit which is in favorable conditions. But Fried [7] argued that the second approach should be adopted to prevent some extremely disadvantaged DMUs from having some inputs adjusted to be negative (obviously not realistic).

Therefore, the adjustment equation is as below [7]:

$$
\begin{aligned}
& \mathrm{x}_{\mathrm{n}_{\mathrm{i}}}^{\mathrm{A}}=\mathrm{x}_{\mathrm{ni}}+\left[\max _{\mathrm{i}}\left\{\mathrm{z}_{\mathrm{i}} \widehat{\beta}^{\mathrm{n}}\right\}-\mathrm{z}_{\mathrm{i}} \widehat{\beta}^{\mathrm{n}}\right]+\left[\max _{\mathrm{i}}\left\{\widehat{\mathrm{v}}_{\mathrm{n}_{\mathrm{i}}}\right\}-\widehat{\mathrm{v}}_{\mathrm{n}_{\mathrm{i}}}\right], \\
& \mathrm{n}=1, \ldots, \mathrm{N} ; \mathrm{i}=1, \ldots, \mathrm{I} .
\end{aligned}
$$


Where $\mathrm{x}_{\mathrm{n}_{\mathrm{i}}}^{\mathrm{A}}$ and $\mathrm{x}_{\mathrm{ni}}$ are adjusted and observed input respectively. The first square bracket of Equation (4) represents the first adjustment that puts all decision-making unit into a same environment, the most unfavorable environment observed in the sample. The second square bracket of this equation shows the second adjustment that makes all DMUs face the same statistical noise. So far the input of each decision-making unit has been adjusted to the same environmental conditions and statistical noise.

\subsection{Stage 3: The Adjusted DEA Model}

Substituting the observed input data $\mathrm{x}_{\mathrm{ni}}$ with the adjusted input data $\mathrm{x}_{\mathrm{n}_{\mathrm{i}}}^{\mathrm{A}}$ while observed output data are unchanging, BCC model is used again to re-evaluate the efficiency of DMUs. In this way, a relatively more accurate results that bear a more realistic reflection of managerial efficiency and scale efficiency can be obtained.

\section{INDEX SELECTION AND DATA SOURCE}

The selection of appropriate indexes is an essential precondition for effective evaluation. Considering that zero should be avoided in input and output data for DEA [9] and taking into account the availability of data, the selected index system and descriptive statistics of the input and output are presented in Table 1.

\subsection{Input and Output}

This article chose two input variables and three output variables, by drawing distinctions among the concepts of statistical indexes and referring to the explanation of statistical indicators in Key Points for Review of Statistical Annual Reports of Humanities and Social Sciences Research in National Colleges and Universities.

In terms of input indexes, the number of R\&D personnel invested in humanities and social science research of each normal university in 2018 is chosen as human resources input and it should be noted that R\&D personnel in this article refers to those who directly participate in scientific research activities or management and provide direct services for scientific research activities. Internal expenditure of each university for humanities and social science research and development in 2018 was selected as the amount of financial input.

In terms of output indexes, this article selects widely adopted output indexes, including the number of completed projects in 2018, the number of monographs published in 2018 and the number of papers published in
2018. To avoid too many zeros, output variable of the number of national or ministerial awards is excluded due to only a minority of universities were awarded.

\subsection{Environment Variables}

Since the environmental effects need to be eliminated in Stage 2, whether the omission of influential variables or the redundancy selection of unnecessary variables will compromise the accuracy of the final result. Based on the principle that the environment variables should not be controlled by the DMU itself but do affect the efficiency of DMU, three environment variables are specified: macroeconomic environment measured by GDP per capital of the city where the school is located in 2018, the distribution of higher education in 2018 and educational level of the local people, among which there are several points supposed to be explained. The first one is that high-quality economic development of the university's location is not only innovation-driven, but also depends on the support of humanities and social sciences; therefore, the economic situation of the region where the university is located can often reflects the local requirements for innovation and development of humanities and social science research, and at the same time affects the research and development funds that the university can obtain Secondly, the research environment defined as distribution of higher education in 2018 is calculated by the ratio of number of universities in the city where the university is located to number of universities in the province where the university seats; the higher the ratio, the more likely it is for scientific research cooperation between universities, and to a certain extent, resource sharing can be achieved. At the same time, it can also make the atmosphere of scientific research and innovation more conducive to the improvement of scientific research efficiency. Lastly, educational environment is measured by the proportion of population with a college degree in the province where the university is located during the sixth national census; it's generally believed that the higher the proportion, the higher the education level of the labor force in the university's location, the larger the scale of human resources for scientific research and innovation activities, the more conducive to the improvement of scientific research efficiency.

\subsection{Data Source}

All data in this article are taken from the annual statistic on the humanities and social sciences of Chinese universities website [10], from which statistics of 98 undergraduate normal colleges and universities across the country are extracted. 
Table 1 Evaluation Indexes and Descriptive Statistics (2018)

\begin{tabular}{|c|c|c|c|c|}
\hline Indicators & Variables & Definition & Mean & $\begin{array}{l}\text { Standard } \\
\text { Deviation }\end{array}$ \\
\hline \multirow[t]{3}{*}{ Input } & Human resources input & $\begin{array}{l}\text { Number of R\&D } \\
\text { personnel in } 2018\end{array}$ & 773.17 & 709.17 \\
\hline & $\begin{array}{l}\text { Financial input } \\
\text { [thousand RMB] }\end{array}$ & $\begin{array}{c}\text { Internal R\&D } \\
\text { expenditure in } 2018\end{array}$ & 32020.09 & 42950.81 \\
\hline & Number of research projects & $\begin{array}{l}\text { Number of completed } \\
\text { projects in } 2018\end{array}$ & 682.46 & 638.39 \\
\hline \multirow[t]{2}{*}{ Output } & Number of monographs & $\begin{array}{l}\text { Number of monographs } \\
\text { published in } 2018\end{array}$ & 45.84 & 62.56 \\
\hline & Number of papers & $\begin{array}{l}\text { Number of papers } \\
\text { published in } 2018\end{array}$ & 476.71 & 449.32 \\
\hline \multirow[t]{3}{*}{$\begin{array}{l}\text { Environment } \\
\text { variables }\end{array}$} & $\begin{array}{c}\text { Macroeconomic } \\
\text { Environment } \\
{[\mathrm{RMB}]}\end{array}$ & $\begin{array}{l}\text { GDP per capital of the } \\
\text { city where the school is } \\
\text { located in } 2018\end{array}$ & 62698.70 & 26302.38 \\
\hline & $\begin{array}{c}\text { Research environment } \\
{[\%]}\end{array}$ & $\begin{array}{c}\text { The distribution of higher } \\
\text { education in } 2018\end{array}$ & 28.18 & 3.07 \\
\hline & $\begin{array}{c}\text { Educational } \\
\text { environment [\%] }\end{array}$ & $\begin{array}{l}\text { Educational level of the } \\
\text { local people }\end{array}$ & 9.48 & 4.76 \\
\hline
\end{tabular}

\section{EMPIRICAL ANALYSIS AND RESULTS}

Firstly, SPSS.20 was used to perform Pearson correlation analysis on the input and output data. According to the results, the Pearson correlation coefficients were positive (see Table 2 for specific results), and passed the two-sided test at the level of $1 \%$, indicating that the input-output indexes meet the isotropic condition assumption of DEA model application.

Table 2 Pearson correlation analysis of input and output

\begin{tabular}{|c|c|c|c|}
\hline \multirow[t]{2}{*}{ Input } & \multicolumn{3}{|c|}{ Output } \\
\hline & $\begin{array}{c}\text { Number of } \\
\text { completed projects }\end{array}$ & $\begin{array}{c}\text { Number of published } \\
\text { monographs }\end{array}$ & $\begin{array}{c}\text { Number of published } \\
\text { papers }\end{array}$ \\
\hline Number of R\&D & $.703^{* *}$ & $.638^{\text {** }}$ & 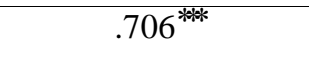 \\
\hline personnel & .000 & .000 & .000 \\
\hline Internal R\&D & $.762^{* *}$ & $.779^{* * *}$ & $.805^{* *}$ \\
\hline expenditure & .000 & .000 & .000 \\
\hline
\end{tabular}


Note: ${ }^{*}$ Significance at the $5 \%$ level.

\subsection{Stage 1: The Estimated Results of Traditional DEA Model}

At this stage, DEAP 2.1 was used to measure the research efficiency of humanities and social sciences of 98 normal universities in China in 2018. The mean of comprehensive technical efficiency, pure technical efficiency and scale efficiency are $0.369,0.488$ and 0.796 , respectively, showing that the overall scientific research efficiency of normal universities in China is low (see Table 4). Since the current result is affected by environmental factors and statistical noise, it is necessary to remove the environmental and statistical influence at the second stage for further evaluation.
This stage takes stage 1 slacks of input as dependent variables and takes environment variables as independent variables. To avoid the problem that the dimensions are not unified, all environment variables received Z-score standardized processing. Two SFA regressions are conducted via Frontier 4.1 and the results are summarized in Table 3. Seen from Table 3, a likelihood ratio test rejected the original hypothesis at $1 \%$ of significant level, indicating that using the SFA model for analyze is appropriate. The results summarized in Table 3 also suggest that the regression coefficients of all environment variables are significant at the level of $1 \%$ or $5 \%$, indicating that all environmental factors selected matter a lot on the degree of input redundancy.

\subsection{Stage 2: SFA Regression Analysis}

Table 3 The second stage: SFA regression results

\begin{tabular}{ccccc}
\hline & \multicolumn{4}{c}{ Dependent variable } \\
\cline { 2 - 5 } Independent variable & Human resources input slack & Financial input slack \\
\cline { 2 - 5 } Constant & $104.323^{* *}(58.391)$ & $2049.37^{*}$ & $(1.984)$ \\
Macroeconomic Environment & $-22.310^{* *}$ & $(-3.744)$ & $-5963.65^{* *}$ & $(-5.822)$ \\
Research environment & $-44.173^{* *}$ & $(-7.211)$ & $-2004.69^{*}$ & $(-2.628)$ \\
Educational environment & $32.018^{* *}$ & $(3.890)$ & $7582.97^{* *}$ & $(4.325)$ \\
$\sigma^{2}$ & $444891.300^{* *}(44891.300)$ & $930239330.00^{* *}(930088950.000)$ \\
$Y$ & $0.999^{* *}$ & $(200.710)$ & $0.989^{* *}$ & $(174.622)$ \\
Log- likelihood function & -708.199 & -1079.281 \\
LR test of the one-side error & \multicolumn{2}{c}{45.285} & 52.37
\end{tabular}

Note: ${ }^{*}$ Significance at the $5 \%$ level (2-tailed), ${ }^{*}$ significance at the $1 \%$ level (2- tailed). The number in the bracket is corresponding estimated $\mathrm{t}$ statistical amount.

As is revealed in the second row of Table 3, macroeconomic environment has been confirmed as having a positive impact of research efficiency (Mengyuan \& Chunjie [11] specified that negative coefficient shows that the increase of environment variable will be favoring for reducing waste of each input). That is to say, universities located within wealthier regions are more efficient. Macroeconomic environment of university location shows a negative relationship with the slacks of number of R\&D personnel. The reason is that regions with higher levels of economic development need to be supported by a larger number of achievements of scientific research, leading to an expanding demand for scientific researchers, thus contributing to the decrease of slacks of human resources input. Meanwhile, economic level is favorable for reducing input redundancy of internal $R \& D$ expenditure. It is because the higher the level of economic development, the greater the demand for scientific research achievements and the stronger the ability to rationally allocate financial resources, the more capable of making full use of financial resources.

What's more, scientific research environment has a negative relationship with human resource input redundancy. It can be speculated that when higher education is more concentrated in a city, scientific researchers have a broader research platform and can flow to various universities more reasonably, thereby effectively avoiding the problem that marginal labor 
productivity of scientific researchers will decline due to excessive concentration of researchers in a certain university; it's worth noting that the concentrated distribution of universities also has a negative relationship with financial resource input redundancy, suggesting that the cooperation and sharing of scientific research resources among universities offer a favorable environment for reducing the redundancy of financial input and better improve the efficiencies of researches, which corresponds with anticipation.

Furthermore, the educational environment characterized by the education level of the population at universities location has a positive impact on the redundancy of human resources input, which is often closely related to the segmented labor market system.

In summary, environment variables have significant effects on the research efficiency of humanities and social sciences in 98 normal universities in China, and the mechanisms and effects are distinct from each other. This further proves the necessity of eliminating environmental factors and statistical noise at this stage. Using equation (4), this article adjusts two observed input.

\subsection{Stage 3: DEA Empirical Analysis Using Adjusted Data}

After obtaining the adjusted input in the second stage, we use Deap2.1 again to re-estimate the scientific research efficiency of the sample. The specific results of each school are not reported here due to space constraints. After adjustment, the average of comprehensive technical efficiency, pure technology efficiency and scale efficiency are $0.431,0.581$ and 0.762 , respectively. Compared with the first stage, comprehensive technical efficiency and pure technology efficiency both increased somewhat, while the scale efficiency slightly decreased. Then, we use SPSS.20 software to perform paired sample $t$ test for further comparison (see Table 4). It shows that except for the scale efficiency, there are significant differences in the results before and after the adjustment, which once again proves the necessity of eliminating environmental effects and statistical noise in order to obtain a more accurate efficiency. In addition, it can be found that the low comprehensive technical efficiency is still mainly caused by the low pure technical efficiency which has considerable room for improvement.

More specifically, Zhengzhou Normal University, Daqing Normal University and Gannan Normal University are still at the forefront of efficiency; Inner Mongolia Normal University and Jiangxi Normal University changed from being inefficient to being at the frontier of efficiency after adjustment. Besides, the adjusted pure technical efficiency of 8 universities including Beijing Normal University, East China Normal University, Shaanxi Normal University and Hubei Normal University are all 1, indicating that these universities enjoy high management efficiency or high scientific research level in Humanities and Social Sciences research and the reason why their comprehensive technical efficiencies fall out of the efficient forefront is that more efforts need to be made to improve scale efficiency.

Table 4 Comparison of results before and after adjustment (2018)

\begin{tabular}{llll}
\hline & $\begin{array}{l}\text { Mean of } \\
\text { TE }\end{array}$ & $\begin{array}{l}\text { Mean of } \\
\text { PTE }\end{array}$ & $\begin{array}{l}\text { Mean } \\
\text { of SE }\end{array}$ \\
\hline $\begin{array}{l}\text { Unadjusted } \\
\text { Stage 1) }\end{array}$ & 0.369 & 0.488 & 0.796 \\
$\begin{array}{l}\text { Adjusted } \\
\text { (Stage 3) }\end{array}$ & 0.431 & 0.581 & 0.762 \\
$\begin{array}{l}\text { Paired } \\
\text { sample t test }\end{array}$ & $\begin{array}{l}\mathrm{p}=0.000 \\
\mathrm{t}=-636,\end{array}$ & $\begin{array}{l}\mathrm{p}=-7.910,000 \\
\mathrm{t}=1.124 \\
\mathrm{p}=0.264\end{array}$ \\
\hline
\end{tabular}

Note: TE stands for comprehensive technical efficiency, PTE stands for pure technical efficiency, $\mathrm{SE}$ stands for scale efficiency, TE$=\mathrm{PTE} \times \mathrm{SE}$.

\section{CONCLUSION AND POLICY INSPIRATION}

Based on the section data in 2018, this article has employed the three-stage DEA model to evaluate the relative research efficiency of humanities and social science in 98 Chinese normal universities, and the conclusions are as below.

First, on the whole, the adjusted average comprehensive technical efficiency of our sample is 0.431 , the average pure technical efficiency is 0.581 , and the average scale efficiency is 0.762 . It shows that the pure technical efficiency and scale efficiency of humanities and social science research in China normal universities remain to be improved, and pure technical efficiency has more considerable room for improvement.

Second, the average comprehensive technical efficiency of 9 normal universities participating in "Double first-class" university project or "Double first-class" discipline project is 0.448 (see Table 5), which is higher than the overall average (0.431). Decomposing this result, the mean pure technical efficiency of these 9 normal universities is 0.635 , which is significantly higher than the mean of overall pure technical efficiency (0.581), showing that these universities not only have outstanding comparative advantages in the research of corresponding disciplines, but also achieve coordinated development of scientific research and discipline construction internally. And this in turn provides an important basis for a new round of discipline resource allocation. However, the average scale efficiency of these 9 "double first-class" normal universities is 0.732 , which is slightly lower than the overall average scale efficiency of 0.762 ; and the returns to scale of these 9 normal universities are all diminishing without exception, which have similarities to conclusions of Xu Aiping and Zhang Fen [12]. A possible explanation 
may lie in the fact that their strong ability to attract scientific research funds and scientific researchers is prone to redundant research funds and human resources input (as the current situation). Therefore, the input structure of scientific research resources remains to be adjusted to improve scale efficiency and change the situation of diminishing returns to scale.

Third, what is of concern is that the comprehensive technical efficiency of normal colleges varies greatly, with a minimum value of 0.191 and a maximum value of 1 , reflecting a low degree of coordinated development among normal universities. That is to say, a situation where normal universities give a full play of their complementary advantages, share their discipline resource and create the academic exchange platform together has not yet been achieved.

Table 5 Research Efficiency of 9 Normal Universities participating in "Double first-class" university project or "Double first-class" discipline project

\begin{tabular}{|c|c|c|c|c|c|c|c|c|}
\hline School name & \multicolumn{4}{|c|}{ Stage 1 (unadjusted) } & \multicolumn{4}{|c|}{ Stage 3 (adjusted) } \\
\hline & $\mathrm{TE}$ & PTE & SE & $\begin{array}{l}\text { Returns } \\
\text { to scale }\end{array}$ & $\mathrm{TE}$ & PTE & SE & $\begin{array}{c}\text { Return } \\
\text { s to } \\
\text { scale }\end{array}$ \\
\hline $\begin{array}{c}\text { Beijing Normal } \\
\text { University }\end{array}$ & 1 & 0.327 & drs & 0.604 & 1 & 0.604 & drs & \\
\hline $\begin{array}{c}\text { Capital Normal } \\
\text { University }\end{array}$ & 0.225 & 0.768 & drs & 0.233 & 0.239 & 0.975 & drs & \\
\hline $\begin{array}{c}\text { Northeast Normal } \\
\text { University }\end{array}$ & 0.623 & 0.246 & drs & 0.306 & 0.554 & 0.552 & drs & \\
\hline $\begin{array}{c}\text { East China Normal } \\
\text { University }\end{array}$ & 1 & 0.459 & drs & 0.680 & 1 & 0.68 & drs & \\
\hline $\begin{array}{l}\text { Nanjing Normal } \\
\text { University }\end{array}$ & 0.624 & 0.369 & drs & 0.444 & 0.576 & 0.771 & drs & \\
\hline
\end{tabular}

Accordingly, the policy inspirations of this article lie in that Chinese normal universities should further improve the internal management efficiency, attach great importance to perfecting the mechanism of innovative talent's introduction as well as the system of using scientific research funds, and strive to create an internal scientific research management with synergistic advantages. At the same time, it is of great necessity to strengthen exchanges and cooperation of humanities and social sciences among normal universities so as to realize common development of the universities and of the humanities and social sciences, laying a solid foundation for building a national innovation system with Chinese characteristics under the guidance of Xi Jinping's thoughts of socialism with Chinese characteristics in the new era. 


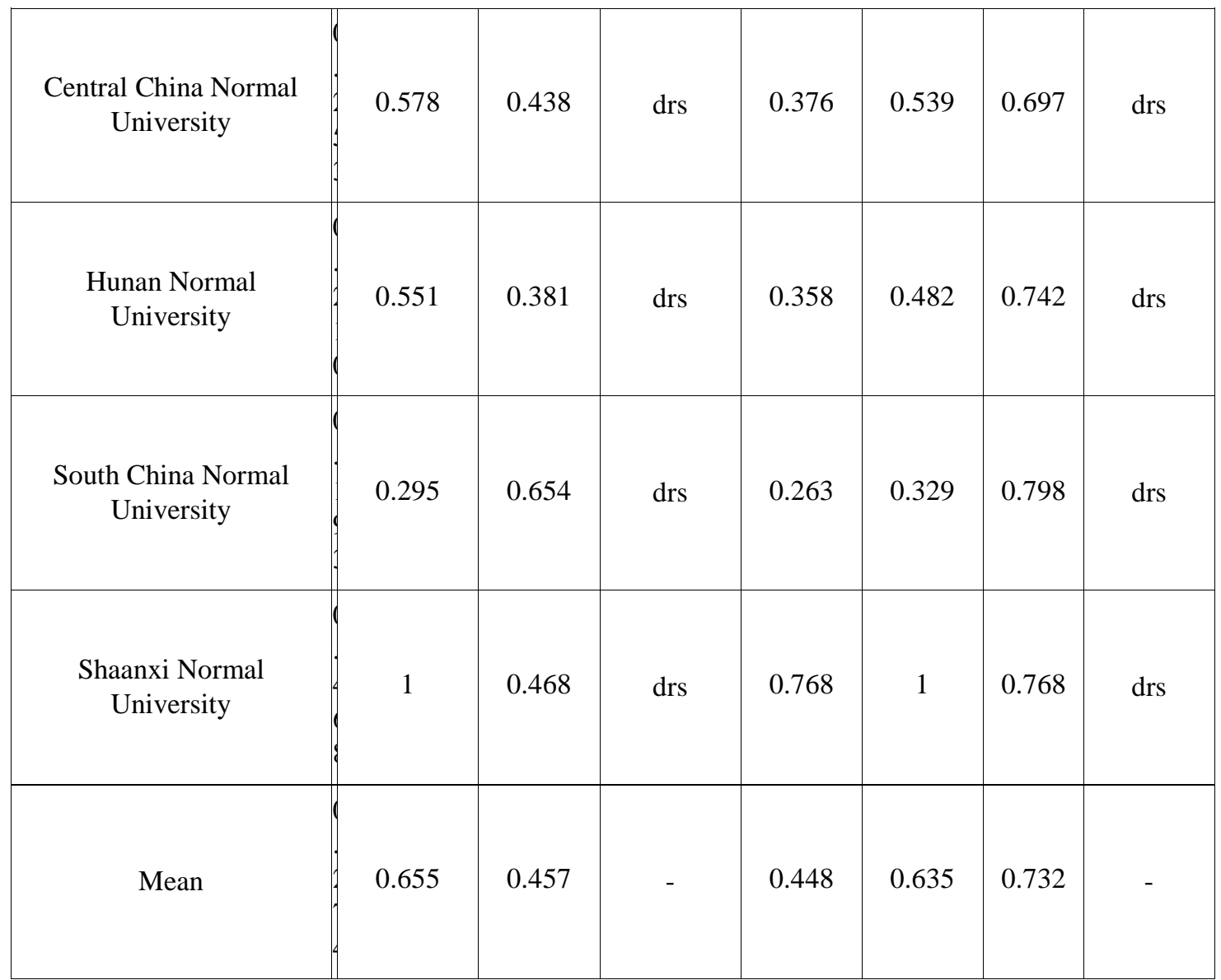

Note: TE, PTE and SE have the same meaning as above. And drs means diminishing returns to scale.

\section{REFERENCES}

[1] Brundenius C, Bo G, Carvalho de Mello, José Manoel. (2017). Universities, Inclusive Development and Social Innovation $\|$. Springer International Publishing.

[2] Ma Ruimin, Zhang Xin, Lang Yongjie. The analysis on humanities and social sciences competitiveness of Chinese undergraduate universities [J]. Journal of Chongqing University (Social Science Edition), 2017,23 (04): 70-78

[3] Shen Neng, Gong Weitian. Evaluation and spatial patterns of university's innovation efficiency in China based on three-stage DEA Model [J]. Science Research Management, 2013, 34 (S1): 125-132

[4] Chen Lu, Ling Duanxin, Sun Yuting. Analysis on Research Efficiency of Humanities and Social Sciences of Universities in Jiangsu Province Based on Three-stage DEA Model [J]. Science \&Technology and Economy, 2018, v.31; No.183 (03): 10- 14.
[5] Charnes, A., Cooper, W. W., \& Rhodes, E.. (1978). Measuring the efficiency of decision making units. European Journal of Operational Research, 2(6), 429-444.

[6] Li Ying, Cui Yuwei. Evaluation of S\&T Innovation Efficiency of Chinese Provincial Colleges: A Three Stage DEA-Based Study [J]. Journal of Northeast Normal University (Philosophy and Social Sciences), 2011 (2): 177-181.

[7] Fried, H. O., Lovell, C. K., Schmidt, S. S., \& Yaisawarng, S. (2002). Accounting for environmental effects and statistical noise in data envelopment analysis. Journal of productivity Analysis, 17(1-2), 157-174.

[8] Luo Dengyue. A note on estimating managerial inefficiency of three-stage DEA mode [J]. Statistical Research, 2012, 29 (04): 104-107.

[9] Cheng Gang. Data Envelopment Analysis Method and MaxDEA Software [M]. Intellectual Property Press, 2014: 181 
[10] Information on https://www.sinoss.net/tongji/

[11] Jiang, M., \& Qi, C. (2018). Measurement and Analysis of Agricultural Production Efficiency in Taiwan of China Based on Three-stage DEA Model. Asian Agricultural Research, 10(1812-2019-003), 10-18.

[12] Xu Aiping, Zhang Fen. Evaluation of Scientific Research Efficiency and Analysis of Regional Differences in "Double First-Class" Construction [J]. STUDIES OF FINANCE AND ACCOUNTING IN EDUCATION, 2018, 29(06):17-24. 